\title{
Gastos com pagamentos no Programa Aqui Tem Farmácia Popular: evolução entre 2006-2014
}

\section{| ${ }^{1}$ Rondineli Mendes da Silva, ${ }^{2}$ Rosângela Caetano |}

Resumo: A partir de 2004, o Governo Federal anunciou o "Programa Farmácia Popular do Brasil", para melhorar o acesso da população brasileira aos medicamentos. A vertente "Aqui Tem Farmácia Popular" (ATFP), iniciada em 2006, tem sido a principal responsável pela expansão dessa forma de provisão. Este artigo examinou os dispêndios do Ministério da Saúde com pagamentos de medicamentos aos estabelecimentos credenciados ao Programa ATFP, no período 2006 a 2014. Foram utilizados dados de fontes secundárias, como o Fundo Nacional de Saúde e a Sala de Apoio à Gestão Estratégica e contato direto com o sistema e-SIC. Gastos do ATFP foram mapeados segundo a indicação de uso dos medicamentos, pelas empresas credenciadas, e também comparados ao repasse ministerial dedicado ao financiamento do Componente Básico da Assistência Farmacêutica. No período, foram gastos $\mathrm{R} \$ 7,9$ bilhóes com o ATFP, com forte padrão de crescimento após a entrada, em 2011, da isenção de copagamento. Medicamentos para tratamento da hipertensão arterial somaram $60 \%$ dos gastos, seguido dos antidiabéticos (19\%) e dislipidemia (14\%). Losartana potássica e sinvastatina obtiveram destaque nos gastos. Os aumentos expressivos nos gastos federais devem ser objeto de monitoramento cuidadoso, já que sustentabilidade financeira é questáo fundamental na viabilidade dos sistemas de financiamento de medicamentos.
'Escola Nacional de Saúde Pública Sergio Arouca, Fundação Oswaldo Cruz. Rio de Janeiro-RJ, Brasil (rondineli.mendes@gmail.com). ORCID: 0000-0002-6243-5179.

${ }^{2}$ Instituto de Medicina Social, Universidade do Estado do Rio de Janeiro. Rio de Janeiro-RJ, Brasil (caetano.r@gmail.com). ORCID: 0000-0003-1480-2453.
Recebido em: 08/08/2017 Aprovado em: 31/102/17 Revisado em: 29/01/2018

> Palavras-chave: Assistência Farmacêutica; custos de medicamentos; gastos em saúde; programas governamentais; Programa Farmácia Popular do Brasil. 


\section{Introdução}

A Assistência Farmacêutica (AF) tem sido tratada de maneira mais abrangente e integrada no contexto das políticas de acesso universal à saúde. Seu espectro de açôes no âmbito da saúde coletiva, associada ao sistema sanitário, proporciona resolubilidade na organização do sistema e das práticas de saúde, em resposta às necessidades da população (OSORIO-DE-CASTRO et al., 2014). Este campo mobiliza um conjunto de atividades de caráter assistencial e gerencial, tendo destaque pela alocação de grande volume de recursos financeiros, tanto públicos como privados.

A Organização Mundial de Saúde reporta que os gastos per capita com medicamentos variaram de US\$ 7,6 a US\$ 431,6, em 2006, em países de baixa e alta renda, respectivamente, apresentando diferenças consideráveis entre os grupos de renda em cada país. Cerca de $80 \%$ dos gastos globais em medicamentos concentram-se em países de alta renda, que possuem apenas $16 \%$ da população mundial, demonstrando profundo padrão de desigualdade. Além disso, nos países de melhor situação econômica, os gastos públicos são o principal componente dos gastos per capita com medicamentos (LU et al., 2011).

A proporção das despesas totais de saúde com medicamentos tem crescido nos países, independentemente de sua categoria de renda. Nesse sentido, a Organização para a Cooperação e Desenvolvimento Econômico assinalou que, durante a década de 1990, as despesas farmacêuticas excederam fortemente às taxas de crescimento dos gastos totais em saúde, permanecendo acima da média do crescimento econômico de seus países membros em 2005 (OECD, 2008).

No Brasil, alguns estudos ta mbém apontam na mesma direção. Entre 2002 e 2006, os gastos totais do setor público com medicamentos aumentaram aproximadamente $115 \%$, enquanto o crescimento do orçamento do Ministério da Saúde (MS) e o do produto interno bruto brasileiro foram de 9,64\% e 14,44\%, respectivamente (CALIARI; RUIZ, 2010). Vieira (2009) mostrou que o gasto do Governo Federal com medicamentos para fornecimento gratuito no Sistema Único de Saúde (SUS) em relação ao gasto total com saúde aumentou, de $5,4 \%$, em 2002, para $10,7 \%$, em 2007. Essa situação traz à tona a necessidade de maior atenção e monitoramento dessa despesa no SUS, em função do potencial impacto nas finanças públicas. 
Essa atenção revela-se ainda mais relevante porque, a despeito do crescimento citado, o acesso aos medicamentos continua representando uma condição desafiadora aos gestores públicos, pois parcela significativa de usuários de serviços privados ou públicos de saúde não possui garantia da assistência farmacêutica (PANIZ et al., 2010; HELFER et al., 2012). Isso se expressa no substancial volume de gastos privados das famílias brasileiras com a compra direta de medicamentos, sobretudo porque as famílias mais pobres comprometem, proporcionalmente, muito mais seu orçamento na aquisição de fármacos (IBGE, 2010, 2004).

Visando melhorar o acesso aos medicamentos, o Programa Farmácia Popular do Brasil (PFPB) foi introduzido na agenda política de saúde brasileira em 2004. Até 2006, o PFPB estava organizado apenas por uma rede pública de farmácias, em vertente chamada "Rede Própria". A partir de então, e com o objetivo de viabilizar sua ampliação, foram instituídas parcerias com o setor privado varejista farmacêutico, componente denominado "Aqui Tem Farmácia Popular" (ATFP). O ATFP foi responsável pela forte expansão e pelo aumento da cobertura do Programa (EMMERICK et al., 2015; SILVA e CAETANO, 2015).

O ATFP disponibiliza um elenco de 41 medicamentos, além de produtos como fraldas geriátricas. Possuindo orçamento, características e gestão definidos unicamente pelo Ministério da Saúde, tem financiamento independente do Componente Básico da Assistência Farmacêutica (CBAF), presente no bloco de financiamento Assistência Farmacêutica, no SUS.

O Programa Farmácia Popular é marcado pelo compartilhamento de custos com os usuários beneficiados, quando da aquisição de alguns medicamentos, e pela isenção de cofinanciamento para anti-hipertensivos, antidiabéticos e antiasmáticos. Essa modalidade do Programa, iniciada em 2011, com dispensa de copagamento, foi denominada de "Saúde Não Tem Preço" e, na atualidade, cobre 32 produtos (SILVA e CAETANO, 2015).

Cada medicamento no ATFP possui um Valor de Referência (VR), que é a base de preço para pagamento nas vendas efetuadas diretamente nos estabelecimentos credenciados do comércio farmacêutico, na qual todas as operaçôes financeiras do Programa são registradas em sistema informatizado (BRASIL, 2012).

Em que pesem as diferenças entre as bases de financiamento para aquisição de medicamentos no SUS, em especial aqueles para a AF na atenção básica, tem sido 
observado expressivo aumento de valores orçamentários e gastos realizados pelo Ministério da Saúde no Programa ATFP (SILVA, 2014). Embora alguns trabalhos já tenham se voltado a examinar historicamente o Programa Farmácia Popular do Brasil (PINTO, 2008; PEREIRA, 2013), estudos detalhados dos gastos governamentais com sua execução encontram-se ausentes da produção científica nacional, limitandose a trazer informações esparsas referentes a dispêndios, dentro de investigaçóes conduzidas com outras motivaçôes (BUENO et al., 2012; SANTOS-PINTO et al., 2011). As expansôes mais recentes do Programa e os debates em torno do modelo desenvolvido em parceria com o setor privado são outros elementos que apontam para a necessidade e urgência de um exame mais detalhado dos gastos com o ATFP.

Este trabalho teve por objetivo examinar os dispêndios do Ministério da Saúde com pagamentos de medicamentos aos estabelecimentos credenciados ao Programa "Aqui tem Farmácia Popular", vertente privada do Programa Farmácia Popular do Brasil, no período 2006 a 2014.

\section{Metodologia}

Estudo de caráter exploratório, do tipo transversal, com foco nos pagamentos executados pelo Ministério da Saúde ao conjunto de estabelecimentos do comércio farmacêutico varejista conveniado ao Programa "Aqui Tem Farmácia Popular", modalidade do Programa Farmácia Popular do Brasil. Foram mapeados os dispêndios com os pagamentos de medicamentos por essa modalidade no período entre 2006 e 2014, utilizando fontes de dados secundárias de acesso livre e duas estratégias metodológicas complementares para obtenção das informaçôes.

A primeira consistiu na realização de buscas na Sala de Apoio à Gestão Estratégica (SAGE), que permite obter dados e informaçôes produzidas pelo Ministério da Saúde e disponibilizadas em seu portal na internet (http://sage.saude.gov.br/), refletindo os registros financeiros das transferências e pagamentos realizados por meio do Fundo Nacional de Saúde (FNS), gestor financeiro dos recursos do SUS na esfera federal (BRASIL, 2014). Na mesma fonte, é possível identificar tanto as transferências fundo a fundo conforme os blocos de financiamento do SUS, como os registros de pagamentos pelo FNS aos estabelecimentos comerciais vinculados ao Programa ATFP. 
O uso dessa estratégia metodológica permitiu identificar os volumes financeiros pagos às empresas credenciadas, de acordo com seu Cadastro Nacional de Pessoa Jurídica (CNPJ). Entretanto, o registro dos procedimentos de pagamento pelo ATFP segue uma organização específica, onde os valores devidos para estabelecimentos matriz e filial são agrupados e os pagamentos computados exclusivamente para a empresa matriz, independente se estes estabelecimentos se encontram no mesmo município ou unidade federativa. Ademais, não existe um detalhamento dos valores individualmente pagos a cada unidade comercial contida na lista de endereços das farmácias vinculadas ao ATFP nem tampouco são discriminados os medicamentos com as respectivas quantidades adquiridas.

$\mathrm{Na}$ busca de informaçóes mais detalhadas e precisas sobre o volume de pagamentos por medicamentos, foi empregada outra estratégia complementar: o acesso presentemente viabilizado pela Lei de Acesso à Informação, que permite a obtenção de informações públicas a qualquer pessoa, física ou jurídica, com o objetivo de promoção da transparência. Operacionalmente, o levantamento de dados foi realizado por meio do Sistema Eletrônico do Serviço de Informações ao Cidadão (e-SIC). Em resposta às solicitaçôes feitas, foram obtidos todos os gastos do Ministério da Saúde com pagamentos anuais de cada um dos medicamentos do rol do ATFP para cada ano do período coberto pelo estudo.

Além do exame dos gastos totais anuais do Ministério da Saúde com o Programa ATFP, foram realizadas duas análises estratificadas. Na primeira, o perfil do gasto do MS com pagamentos pelos medicamentos foi analisado tomando por base a indicação de uso do medicamento descrita na Portaria n $n^{\text {o. }}$ 971/2012, que regulamentava o Programa na época do estudo (BRASIL, 2012) e a classificação Anatomical Therapeutic Chemical Classification System (ATC), preconizada pela Organização Mundial da Saúde para estudos com fármacos e obtida a partir de consulta à página eletrônica da WHO Collaborating Centre for Drug Statistics Methodology (WHO, 2015). ${ }^{1} \mathrm{Na}$ segunda, os gastos foram classificados segundo a presença de copagamento de cada um dos medicamentos, respeitando as inclusôes de isenção da contrapartida dos usuários ocorridas para produtos antidiabéticos e anti-hipertensivos, em 2011, e para a asma, no ano seguinte.

Os valores totais anuais da contrapartida federal destinados à aquisição de medicamentos do Componente Básico da Assistência Farmacêutica (CBAF) enviados aos municípios foram também mapeados por meio do sítio eletrônico da 
SAGE, permitindo comparaçóes entre estes repasses e os volumes de pagamentos realizados pelo Ministério da Saúde no ATFP. Os dados obtidos foram organizados em planilhas no aplicativo Microsoft Excel ${ }^{\triangleright}$ (Microsoft Corp., Estados Unidos), contendo os pagamentos anuais por unidade federativa, município, nome da entidade comercial credenciada, além dos gastos anuais específicos para cada medicamento/ apresentação presente no rol do ATFP.

Os gastos do Programa ATFP e do volume de repasses com o CBAF por habitante foram estimados para cada ano do período, a partir da divisão entre o volume de recursos dispendidos ou transferidos pelo Ministério da Saúde dentro de cada ano e a população residente estimada pelo Instituto Brasileiro de Geografia e Estatística (IBGE) presente na página eletrônica do Departamento de Informática do SUS (DATASUS, 2015). Os dispêndios no ATFP foram também cotejados com os valores de financiamento per capita do CBAF instruídos nas normativas ministeriais que regularam o financiamento deste Componente, dentro do período temporal sob estudo (BRASIL, 2005; 2007; 2009; 2010; 2013).

Considerando a extensão do período analisado, foi realizada atualização monetária dos valores pelo Índice de Preços ao Consumidor Amplo (IPCA), permitindo compará-los aos valores de 31 de dezembro de 2014, obtidos diretamente no sítio do Instituto de Pesquisa Econômica Aplicada (IPEA), disponível no endereço http:// www.ipeadata.gov.br/. A opção pelo uso desse deflator fundamentou-se na Lei $n^{\circ}$ 10.742/2003, que estabeleceu as normas de regulação do setor farmacêutico e definiu este índice, calculado pelo IBGE, para fins do ajuste nos preços dos medicamentos (IBGE, 2004).

O estudo utilizou apenas dados secundários de acesso público, dispensando submissão ao Comitê de Ética em Pesquisa.

\section{Resultados}

Entre 2006-2014, foram gastos $\mathrm{R}$ \$ 7,9 bilhôes com pagamentos de medicamentos no ATFP. Identificou-se forte padrão de crescimento tanto na expansão de estabelecimentos credenciados (superior a $1.000 \%$ ), como no volume dos gastos com pagamentos realizados pelo Ministério da Saúde ao setor privado do ATFP, de $4.278 \%$ (Gráfico 1). O triênio 2012-2014 concentrou cerca de 70\% dos gastos realizados, com maior volume atingido em 2014 (29\% do total). 
Algumas oscilaçóes nos gastos com ATFP ocorreram no período estudado, com uma interrupção na tendência de crescimento nos volumes dispendidos em 2010. No ano seguinte, com a introdução da isenção de copagamento para anti-hipertensivos e antidiabéticos, os gastos ascenderam fortemente (183\%) e desde então mantiveram tendência de forte crescimento (tabela 1).

Gráfico 1. Expansão do número de farmácias e do gasto do Ministério da Saúde no Programa ATFP com pagamentos de medicamentos, Brasil 2006-2014 (em R\$, corrigidos para 31 de dezembro de 2014)

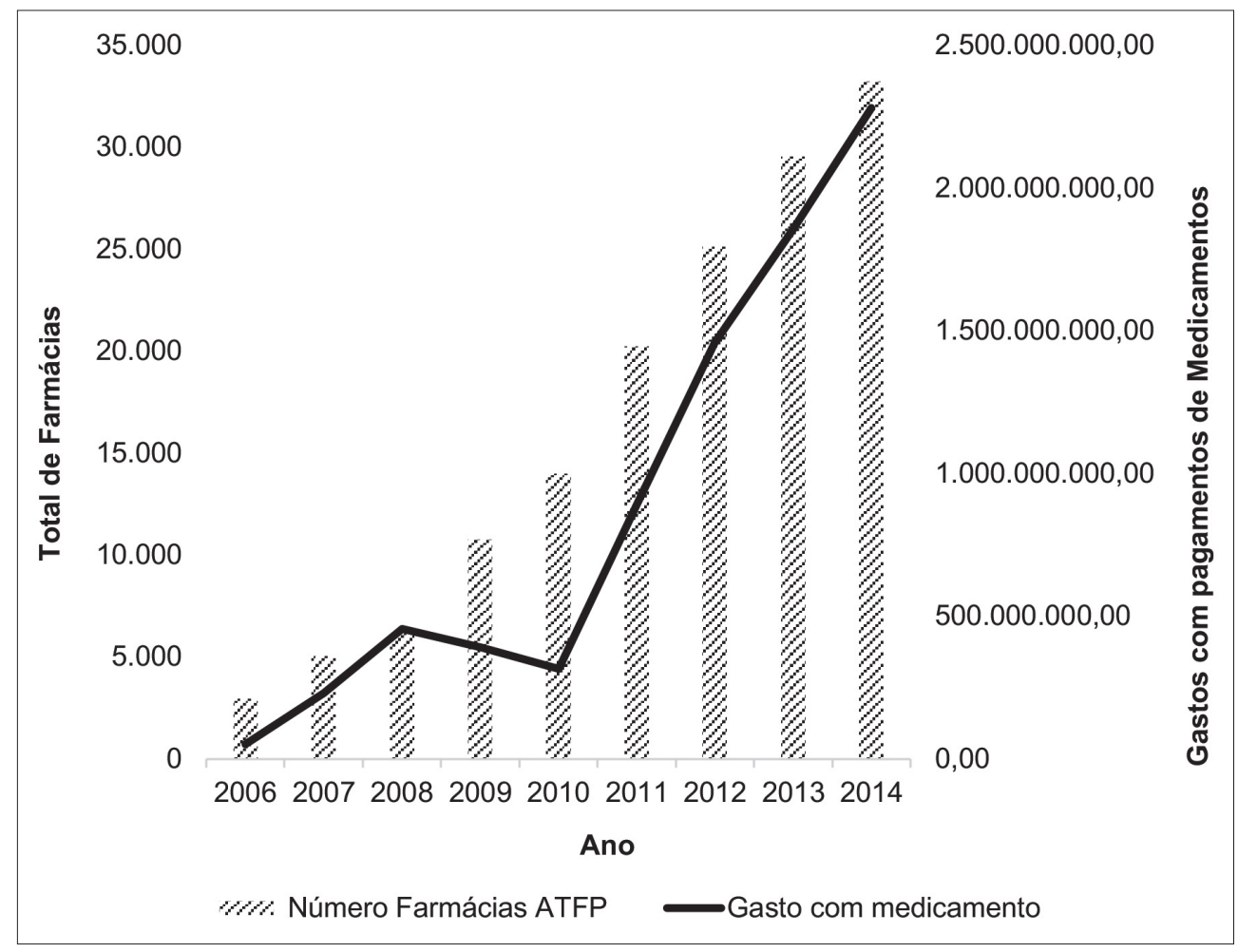

Legenda: ATFP — Aqui Tem Farmácia Popular. 
Tabela 1. Gastos com pagamentos de medicamentos no Programa ATFP e repasses fundo a fundo no CBAF pelo Ministério da Saúde, Brasil 2006-2014 (em R\$, corrigidos para 31 de dezembro de 2014)

\begin{tabular}{llllll}
\hline Ano & $\begin{array}{l}\text { Gastos com } \\
\text { pagamentos no } \\
\text { ATFP }\end{array}$ & $\begin{array}{l}\text { Evoluçáo } \\
\text { percentual } \\
\text { dos gastos } \\
\text { no ATFP }\end{array}$ & $\begin{array}{l}\text { Repasses no } \\
\text { financiamento } \\
\text { do CBAF }\end{array}$ & $\begin{array}{l}\text { Evoluçáo } \\
\text { percentual } \\
\text { nos repasses } \\
\text { do CBAF }\end{array}$ & $\begin{array}{l}\text { Razáo entre } \\
\text { gastos ATFP } \\
\text { e repasses } \\
\text { CBAF }\end{array}$ \\
\hline 2006 & $52.104 .886,67$ & - & $891.191 .336,17$ & - & 0,06 \\
2007 & $230.124 .287,81$ & $342 \%$ & $984.431 .066,36$ & $10 \%$ & 0,23 \\
2008 & $456.156 .668,79$ & $98 \%$ & $1.058 .510 .436,03$ & $8 \%$ & 0,43 \\
2009 & $391.189 .434,73$ & $-14 \%$ & $1.014 .438 .748,52$ & $-4 \%$ & 0,39 \\
2010 & $315.458 .551,99$ & $-19 \%$ & $1.295 .353 .130,78$ & $28 \%$ & 0,24 \\
2011 & $891.866 .965,64$ & $183 \%$ & $1.164 .928 .609,15$ & $-10 \%$ & 0,77 \\
2012 & $1.458 .180 .998,89$ & $63 \%$ & $1.099 .459 .170,66$ & $-6 \%$ & 1,33 \\
2013 & $1.857 .968 .707,30$ & $27 \%$ & $1.063 .814 .821,86$ & $-3 \%$ & 1,75 \\
2014 & $2.281 .267 .001,46$ & $23 \%$ & $1.000 .434 .453,32$ & $-6 \%$ & 2,28 \\
\hline Total & $7.934 .317 .503,28$ & - & $9.572 .561 .772,84$ & - & - \\
\hline Média & $\mathbf{8 8 1 . 5 9 0 . 8 3 3 , 7 0}$ & $\mathbf{8 8} \%$ & $\mathbf{1 . 0 6 3 . 6 1 7 . 9 7 4 , 7 6}$ & $\mathbf{2} \%$ & $\mathbf{0 , 8 3}$ \\
$(\mathrm{DP})$ & $(\mathbf{7 9 8 . 3 9 0 . 4 1 7 )}$ & $(\mathbf{1 2 2} \%)$ & $(116.021 .555)$ & $(13 \%)$ & $(\mathbf{0 , 7 8 )}$ \\
\hline
\end{tabular}

Legenda: ATFP - Aqui Tem Farmácia Popular, CBAF - Componente Básico da Assistência Farmacêutica, DP — Desvio-padrão.

Houve repasses do Ministério da Saúde aos municípios pelo CBAF de R\$ 9,5 bilhôes entre 2006-2014, corrigidos a valores de 31 de dezembro de 2014. Verificouse estagnação nos repasses aos municípios, que mostraram pequeno crescimento de $12 \%$, com flutuaçôes e tímido aumento até 2010. A partir de 2011, sua evolução passou a revelar índices negativos. A média de crescimento do financiamento do CBAF foi muito inferior à dos gastos do Ministério da Saúde com o Aqui Tem Farmácia Popular (2\% contra $88 \%$, respectivamente). Além disso, os pagamentos no ATFP eram menores que os repasses do CBAF até 2011, ultrapassando a contrapartida federal daí em diante. Considerando o último ano de análise, os gastos no Programa foram mais que o dobro do financiamento público da AF básica pelo Ministério da Saúde (tabela 1).

A estimativa dos gastos correntes per capita pagos no ATFP foi superior aos valores mínimos da contrapartida federal ( $\mathrm{R} \$ 5,10$ por habitante/ano) e ao gasto 
médio com repasses por habitante do Ministério da Saúde no CBAF, desde 2012. Em 2014, o gasto no ATFP foi de R\$ 11,20 por habitante/ano, equivalente a mais que o dobro da contrapartida ministerial e maior, inclusive, que o somatório dos valores mínimos dos entes subnacionais ( $\mathrm{R}$ 9,82 por habitante/ano) previstos na Portaria $\mathrm{n}^{\circ} 1.555$ de 2013 (gráfico 2).

Gráfico 2. Pagamentos por habitante no Programa ATFP e repasses do financiamento do CBAF pelo Ministério da Saúde, Brasil 2006-2014 (em R\$, valores correntes)



Fonte: *_valores mínimos de financiamento das Portarias GM/MS 2.084/05, 3.237/07, 2.982/2009, 4.217/10 e 1.555/13.

Legenda: ATFP — Aqui Tem Farmácia Popular, CBAF — Componente Básico da Assistência Farmacêutica.

Segundo a classeATC, quatrogrupos responderam por $75 \%$ dos dispêndios executados pelo Ministério da Saúde no ATFP: inibidores da enzima conversora de angiotensina simples (28\%) e antagonistas da angiotensina II simples (20\%), ambos indicados para tratamento da hipertensão, seguido pelos agentes modificadores de lipídios (14\%) e pelos hipoglicemiantes orais (13\%), para tratamento da dislipidemia e do diabetes, respectivamente (tabela 2). Medicamentos para o tratamento da asma mostraram baixos valores no geral, pois responderam por apenas 3\% dos gastos totais, ainda que tenham sido dispensados de copagamento a partir de junho de 2012. Dispêndios do Ministério da Saúde com pagamento de fraldas comercializadas no ATFP somaram, em valores ajustados a dezembro de 2014, $\mathrm{R} \$ 209.531 .764,23$ (2,6\% do total). 


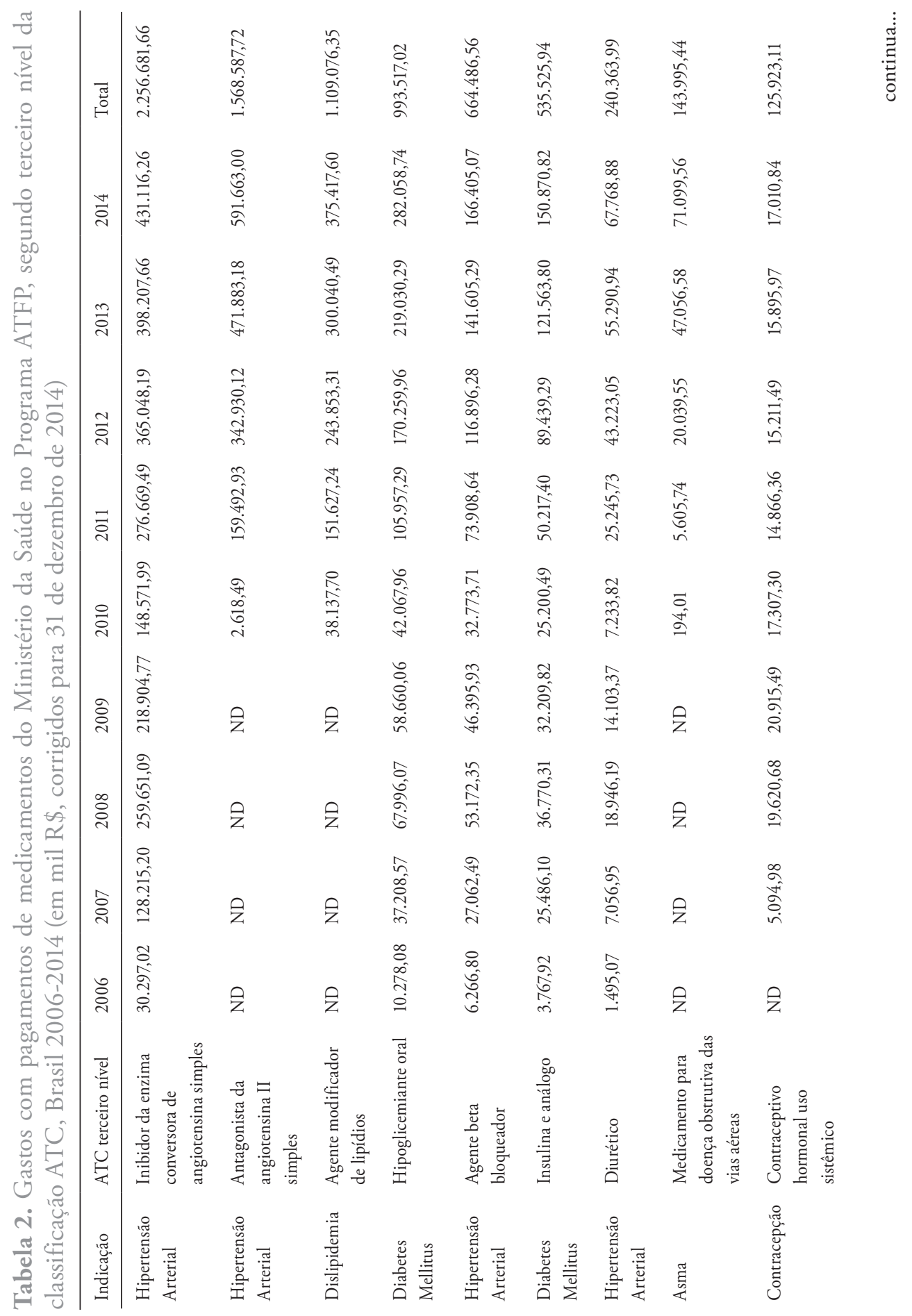


| Página 11 de 30

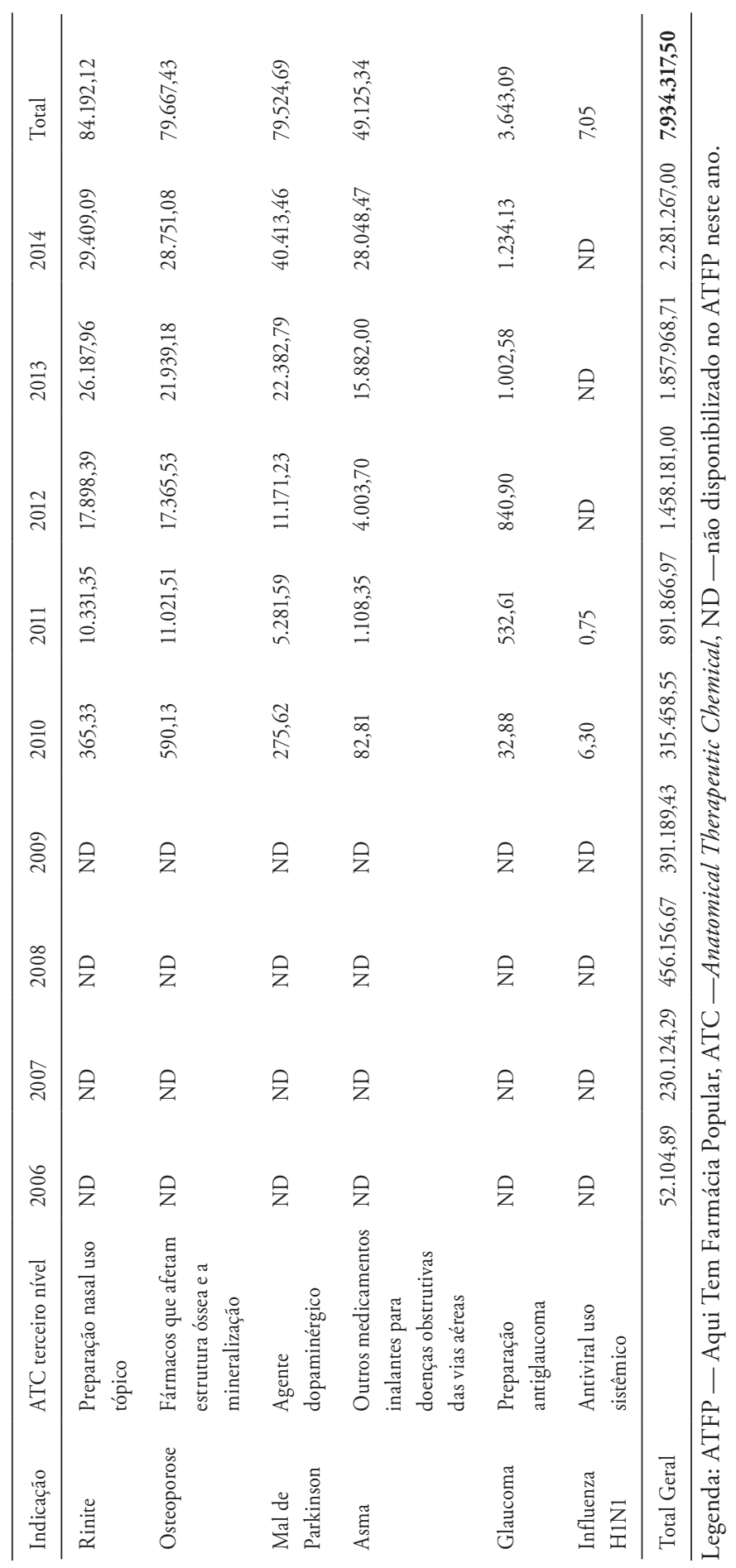


Os gastos do Ministério da Saúde com pagamentos dos cinco principais produtos em cada ano mostraram desconcentração proporcional (de 87,4\%, em 2006, a 61,9\%, em 2014), fruto da incorporação de novos fármacos no decorrer do funcionamento do Programa. Entre 2006-2009, os dispêndios com este conjunto de produtos mantiveram o mesmo padrão, alterando-se apenas a posição dentre eles, com maiores percentuais para medicamentos indicados no tratamento da hipertensão e diabetes (tabela 3).

Tabela 3. Cinco primeiros medicamentos com maior valor de gastos no Programa ATFP, por ano de aquisiçấo, Brasil 2006-2014 (em R \$, corrigidos para 31 de dezembro de 2014)

\begin{tabular}{|c|c|c|c|}
\hline Ano & Descrição do Medicamento & Gasto anual & $\%$ Gasto anual \\
\hline \multirow{6}{*}{2006} & Enalapril $10 \mathrm{mg}$ & $13.099 .098,24$ & 37,3 \\
\hline & Captopril $25 \mathrm{mg}$ & $7.340 .142,75$ & 20,9 \\
\hline & Metformina $850 \mathrm{mg}$ & $4.322 .027,67$ & 12,3 \\
\hline & Atenolol $25 \mathrm{mg}$ & $3.781 .305,47$ & 10,8 \\
\hline & Insulina Humana NPH 100UI/ml Frasco $10 \mathrm{ml}$ & $2.178 .054,98$ & 6,2 \\
\hline & Total & $30.720 .629,11$ & 87,4 \\
\hline \multirow{6}{*}{2007} & Enalapril $10 \mathrm{mg}$ & $61.069 .232,20$ & 37,1 \\
\hline & Captopril $25 \mathrm{mg}$ & $30.524 .352,04$ & 18,6 \\
\hline & Atenolol $25 \mathrm{mg}$ & $16.990 .425,02$ & 10,3 \\
\hline & Metformina $850 \mathrm{mg}$ & $16.053 .661,90$ & 9,8 \\
\hline & Insulina Humana NPH 100UI/ml Frasco $10 \mathrm{ml}$ & $15.433 .337,56$ & 9,4 \\
\hline & Total & $140.071 .008,72$ & 85,2 \\
\hline \multirow{6}{*}{2008} & Enalapril $10 \mathrm{mg}$ & $122.937 .745,09$ & 36,2 \\
\hline & Captopril $25 \mathrm{mg}$ & $70.555 .849,35$ & 20,8 \\
\hline & Atenolol $25 \mathrm{mg}$ & $34.054 .293,66$ & 10,0 \\
\hline & Metformina $850 \mathrm{mg}$ & $29.681 .711,33$ & 8,7 \\
\hline & Insulina Humana NPH 100UI/ml Frasco $10 \mathrm{ml}$ & $23.170 .858,52$ & 6,8 \\
\hline & Total & $280.400 .457,95$ & 82,5 \\
\hline
\end{tabular}

continua... 


\begin{tabular}{|c|c|c|c|}
\hline Ano & Descrição do Medicamento & Gasto anual & $\%$ Gasto anual \\
\hline \multirow{6}{*}{2009} & Enalapril $10 \mathrm{mg}$ & $113.810 .964,95$ & 36,8 \\
\hline & Captopril $25 \mathrm{mg}$ & $59.173 .138,51$ & 19,1 \\
\hline & Atenolol $25 \mathrm{mg}$ & $32.112 .468,61$ & 10,4 \\
\hline & Metformina $850 \mathrm{mg}$ & $25.854 .027,61$ & 8,4 \\
\hline & Insulina Humana NPH $100 \mathrm{UI} / \mathrm{ml}$ Frasco $10 \mathrm{ml}$ & 21.237.613,27 & 6,9 \\
\hline & Total & $252.188 .212,95$ & 81,6 \\
\hline \multirow{6}{*}{2010} & Enalapril $10 \mathrm{mg}$ & $89.839 .973,82$ & 33,8 \\
\hline & Captopril $25 \mathrm{mg}$ & $35.188 .779,55$ & 13,3 \\
\hline & Atenolol $25 \mathrm{mg}$ & $25.150 .619,19$ & 9,5 \\
\hline & Metformina $850 \mathrm{mg}$ & $19.016 .133,01$ & 7,2 \\
\hline & Sinvastatina $20 \mathrm{mg}$ & $18.684 .959,26$ & 7,0 \\
\hline & Total & $187.880 .464,83$ & 70,8 \\
\hline \multirow{6}{*}{2011} & Enalapril $10 \mathrm{mg}$ & $162.948 .990,98$ & 20,5 \\
\hline & Losartana potássica $50 \mathrm{mg}$ & $142.012 .455,72$ & 17,9 \\
\hline & Captopril $25 \mathrm{mg}$ & $83.397 .434,29$ & 10,5 \\
\hline & Sinvastatina $20 \mathrm{mg}$ & $74.075 .675,80$ & 9,3 \\
\hline & Atenolol $25 \mathrm{mg}$ & $58.704 .162,29$ & 7,4 \\
\hline & Total & $521.138 .719,08$ & 65,6 \\
\hline \multirow{6}{*}{2012} & Losartana potássica $50 \mathrm{mg}$ & $323.425 .192,37$ & 23,5 \\
\hline & Enalapril $10 \mathrm{mg}$ & $230.661 .626,36$ & 16,8 \\
\hline & Sinvastatina $20 \mathrm{mg}$ & $123.744 .384,06$ & 9,0 \\
\hline & Captopril $25 \mathrm{mg}$ & $113.623 .623,30$ & 8,3 \\
\hline & Sinvastatina $40 \mathrm{mg}$ & $101.014 .131,87$ & 7,3 \\
\hline & Total & $892.468 .957,96$ & 64,9 \\
\hline
\end{tabular}

continua... 


\begin{tabular}{|c|c|c|c|}
\hline Ano & Descrição do Medicamento & Gasto anual & $\%$ Gasto anual \\
\hline \multirow{6}{*}{2013} & Losartana potássica $50 \mathrm{mg}$ & $471.883 .178,67$ & 25,4 \\
\hline & Enalapril $10 \mathrm{mg}$ & $274.150 .662,43$ & 14,8 \\
\hline & Sinvastatina $20 \mathrm{mg}$ & $159.732 .811,35$ & 8,6 \\
\hline & Sinvastatina $40 \mathrm{mg}$ & $134.344 .039,94$ & 7,2 \\
\hline & Atenolol $25 \mathrm{mg}$ & $128.198 .002,88$ & 6,9 \\
\hline & Total & $1.168 .308 .695,27$ & 62,9 \\
\hline \multirow{6}{*}{2014} & Losartana potássica $50 \mathrm{mg}$ & $591.662 .998,90$ & 25,9 \\
\hline & Enalapril $10 \mathrm{mg}$ & $301.560 .557,71$ & 13,2 \\
\hline & Sinvastatina $20 \mathrm{mg}$ & $193.728 .777,92$ & 8,5 \\
\hline & Sinvastatina $40 \mathrm{mg}$ & $174.952 .059,40$ & 7,7 \\
\hline & Atenolol $25 \mathrm{mg}$ & $151.074 .091,78$ & 6,6 \\
\hline & Total & $1.412 .978 .485,71$ & 61,9 \\
\hline
\end{tabular}

Legenda: ATFP — Aqui Tem Farmácia Popular.

A partir de 2010, algumas mudanças ligadas à introdução de novos medicamentos, como já citado, produziram reflexos nos gastos. Primeiro, a entrada da sinvastatina $20 \mathrm{mg}$ no grupo de principais itens de dispêndio, que continua mostrando-se importante nos gastos dos anos subsequentes. O somatório de suas duas apresentaçôes (20 mg e $40 \mathrm{mg}$ ) é o segundo item de maior relevância dos gastos, exceto para 2012. Outro medicamento merecedor de comentário é a losartana potássica $20 \mathrm{mg}$, fármaco anti-hipertensivo da classe dos antagonistas dos receptores da angiotensina II, que obteve a segunda posição já a partir de 2011, tornando-se o maior item de gasto nos anos seguidos.

O Gráfico 3 examina os gastos no ATFP segundo a exigência de copagamento pelo usuário, respeitando o período de implementação dessa condição ao longo do tempo. Até 2010, todos os medicamentos possuíam cofinanciamento no ATFP e, no geral, produtos com isenção de pagamento responderam por $64 \%$ do total dos gastos ( $\mathrm{R} \$ 5.090 .860 .542,66)$, mas o percentual médio dos gastos foi de 78\% entre 2011-2014. 
Gráfico 3. Gastos do Ministério da Saúde no Programa ATFP com pagamentos de medicamentos, segundo a cobrança de copagamento aos usuários, Brasil 2006-2014 (em $\mathrm{R} \$$, corrigidos para 31 de dezembro de 2014)

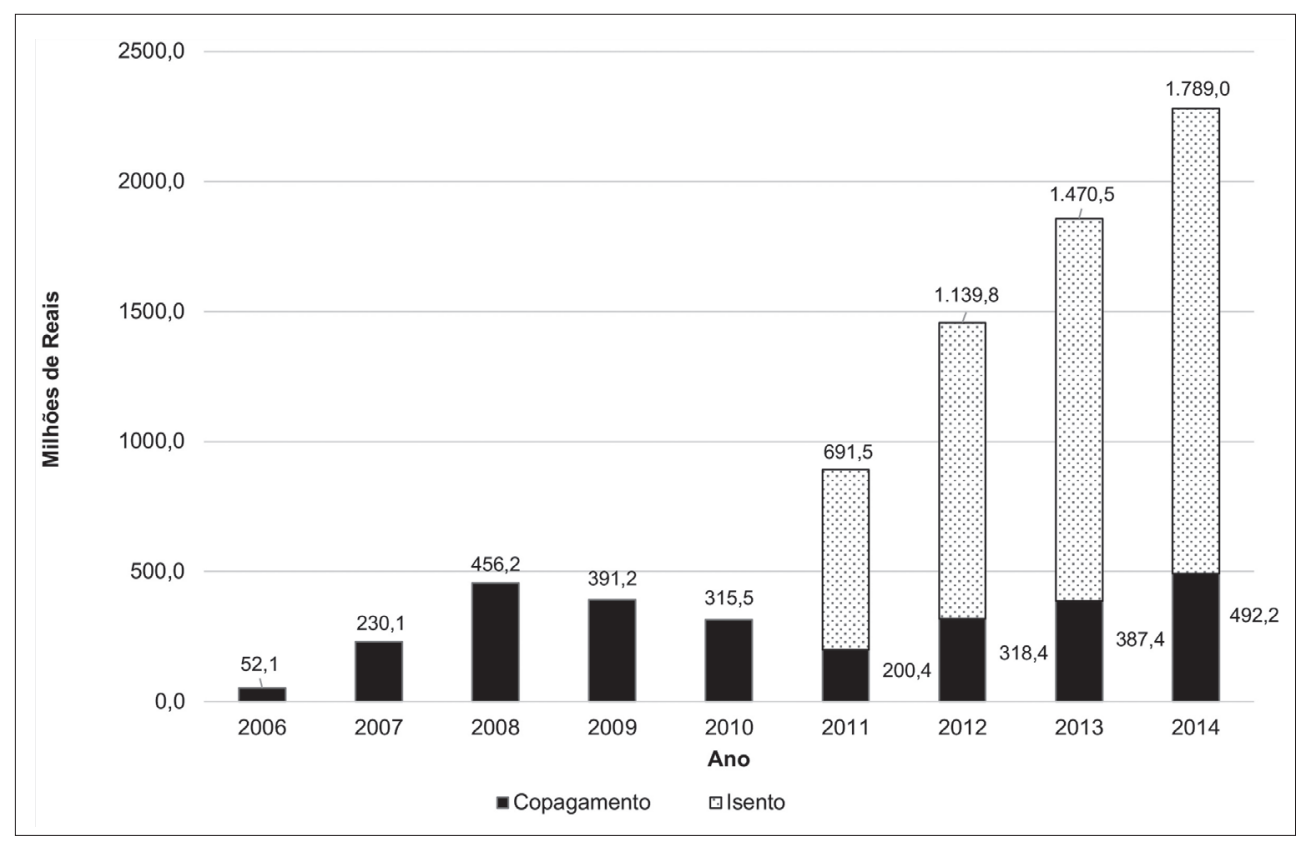

Outro elemento relevante é relativo ao comportamento dos pagamentos efetuados pelo Ministério da Saúde às diferentes entidades do comércio farmacêutico receptoras de recursos no ATFP no contexto nacional. Os vinte maiores estabelecimentos receberam $\mathrm{R} \$ 2.573 .469 .998,87$ em valores corrigidos, que correspondeu a 31,7\% do valor total pago entre 2006-2014; com redução na concentração proporcional dos pagamentos, de 89,4\%, em 2006, para 24,1\%, em 2014 (tabela 4), fruto da entrada, ao longo dos anos, de novas empresas, que capturam recursos de pagamento.

Dos 20 estabelecimentos, 11 empresas, todas localizadas no eixo Rio-São Paulo, responderam por $60,8 \%$ dos quase $\mathrm{R} \$ 2,6$ milhôes pagos, com uma única firma Jamyr Vasconcellos, com sede no Rio de Janeiro — recebendo 20,1\% destes dispêndios e 6,5\% dos pouco mais de R \$ 8,1 bilhóes, somados medicamentos e fraldas. Seguemse, em importância no recebimento dos pagamentos, as empresas Drogasil S.A. (17,9\%), Empreendimentos Pague Menos S.A. (11,9\%), Drogaria São Paulo S.A. (9,2\%), Dimed S.A. (6,8\%), Drogaria Araújo S.A. (6,3\%) e Raia S.A. (5,5\%). 


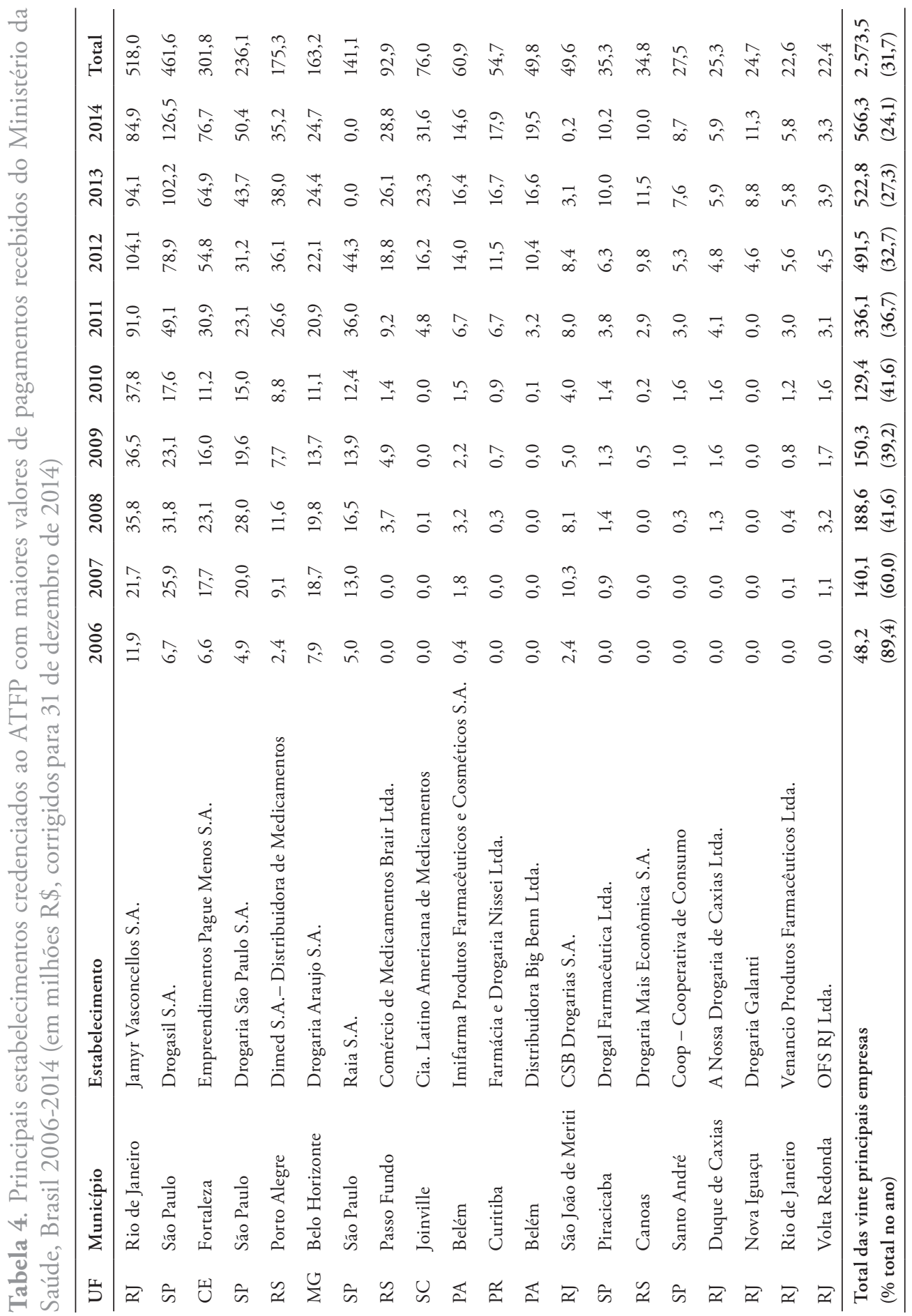


Em termos da distribuição das empresas varejistas pelos estados, destaca-se a região Sul, com firmas presentes em todos os estados: Rio Grande do Sul (três), Santa Catarina e Paraná (uma). O estado do Pará possui dois estabelecimentos comerciais no ranking dos vinte principais, enquanto Ceará e Minas Gerais têm uma única firma.

\section{Discussão}

Os resultados apontam grande expansão do Programa ATFP ocorrida a partir da associação com o comércio varejista farmacêutico, que se expressa no crescimento do volume de gastos com pagamentos de medicamentos entre 2006-2014, que totalizaram pouco mais de $\mathrm{R} \$ 7,9$ milhôes. Houve intenso incremento dos dispêndios a partir de 2011, coincidindo com o início da isenção de copagamento para antihipertensivos, antidiabéticos e, depois, para produtos antiasmáticos, quando da introdução da vertente "Saúde Não Tem Preço".

Entre 2008 e 2010, ocorreu estagnação nos pagamentos pelo Ministério da Saúde, fruto de inúmeras mudanças administrativas, que envolveram vários ajustes, como mudanças nas regras de atendimento da prescrição médica, de armazenamento das informaçóes e de suporte informacional; posteriormente foi retomada ascendente de crescimento explosivo de pacientes e, consequentemente, de gastos, com registros de fornecimento de medicamentos, ligados ao fim do copagamento (SILVA; CAETANO, 2015).

Outros fatos também podem ter contribuído no avanço dos gastos, ao longo da evolução no modelo de parceria público-privada no Programa Farmácia Popular do Brasil. Em primeiro lugar, questôes ligadas à expansão do número de estabelecimentos credenciados, que viabilizou a capilaridade geográfica do ATFP, e aumento de usuários atendidos, que ascendeu fortemente ao longo do período analisado. Alguns estudos ressaltam aumento em mais de 8,5 vezes do número de farmácias habilitadas entre 2006-2013. Até 2012, o ATFP cobria 63,4\% dos municípios brasileiros, correspondendo a nove vezes a cobertura de 2006; essa capilaridade, contudo, não atingia municípios das regiôes Norte e Nordeste, que apresentavam menores coberturas. Municípios com mais de 20.000 habitantes possuíam cobertura percentual de $21,7 \%$, em 2006, e 84,0\%, em 2012, enquanto aqueles com até 20.000 habitantes, iniciaram com o período examinado com baixíssima cobertura $(0,7 \%)$ 
e atingiram 54,6\%, em 2012. No entanto, a penetração do Programa continuou a ser maior no Sul e Sudeste, guardando relaçáo com seus elevados contingentes populacionais (EMMERICK et al., 2015; SILVA; CAETANO, 2015).

Além disso, fatores associados aos sucessivos incrementos no rol de medicamentos ao longo do histórico do Programa ATFP, que iniciou com nove medicamentos em 2006 e atingia 41 itens em 2014, contribuíram também na elevação dos gastos (BRASIL, 2006; 2012). No ano de 2010, ocorreu a maior introdução de produtos (24 ao todo), entre os quais a losartana potássica $50 \mathrm{mg}$, sinvastatina 10, 20 e 40 mg, e várias apresentaçôes de insulina regular, produtos envolvidos em grandes quantitativos de venda e volumes expressivos de gastos (SILVA; CAETANO, 2015).

Os gastos com o conjunto de medicamentos isentos de copagamento têm percentual médio de 78\% entre 2011-2014, muito superiores àqueles itens que permaneceram no sistema de cofinanciamento. Até 2010, todos os medicamentos fornecidos pelas distintas vertentes do Programa Farmácia Popular do Brasil seguiam arranjo de copagamento, no qual os custos com sua aquisição eram compartilhados entre os usuários e o Ministério da Saúde, com parcela de pagamento de até 90\% pagos pelo governo, e a diferença coberta pelo usuário.

Comparaçôes entre os montantes de recursos gastos pelo Ministério da Saúde no Programa Aqui Tem Farmácia Popular e os repasses financeiros do Componente Básico do Bloco da Assistência Farmacêutica aos municípios mostram descompasso na velocidade de crescimento entre ambos. Dispêndios do Ministério da Saúde com o CBAF apresentaram estabilidade ao longo do tempo. Ao contrário, à medida que ATFP avança - seja pelo aumento de estabelecimentos, incorporaçáo de novos medicamentos e, principalmente, pela isenção de copagamento —, verifica-se mudança de posiçáo iniciada em 2011, com gastos do Programa ultrapassando R \$ 1 bilhão em 2012 e atingindo quase R \$ 2,3 bilhôes em 2014 (aumento de 2,6 vezes em relação a 2011), frente ao repasse direto aos municípios para a provisão pública descentralizada de medicamentos que estagna na casa de 1 bilhão, desde 2008.

Isso traz indícios para o questionamento da opção ou prioridade, por parte do Ministério da Saúde, no financiamento público de medicamentos. Estudo de Vieira e Zucchi (2013), que cobriu período entre 2005-2009, mostrou existência de aumento de 20,6 vezes no valor destinado pelo MS ao Programa Farmácia Popular, frisando o modesto crescimento de investimento destinado à estruturação de serviços farmacêuticos públicos. Da mesma forma, Pereira (2013) evidenciou que os valores 
orçamentários dedicados ao ATFP e, também, os pagamentos diretamente executados pelo Ministério da Saúde aos estabelecimentos participantes já representavam parte significativa do financiamento da AF no âmbito do SUS, relativo ao ano de 2012. Já a Associação da Indústria Farmacêutica de Pesquisa aponta, em seu relatório de 2015, a grande diferença no crescimento do orçamento previsto ao ATFP e o somatório dos Componentes da Assistência Farmacêutica (Básico, Estratégico e Especializado), entre os anos de 2010 e 2015. O Programa Aqui Tem Farmácia Popular cresceu $725,7 \%$, enquanto aquele dirigido ao financiamento dos três componentes foi de 52,8\% (ASSOCIAÇÃO DA INDÚSTRIA FARMACÊUTICA DE PESQUISA (INTERFARMA), 2015).

A modalidade ATFP apresentou um montante dispendido elevado. Em 2013, os valores com a modalidade corresponderam a $26 \%$ dos gastos com todas as compras federais de medicamentos (CHAMA et al., 2017). Em 2012, representam o segundo lugar em termos de gastos, dentre os programas ministeriais de assistência farmacêutica, logo abaixo do financiamento do Componente Especializado da Assistência Farmacêutica, com R\$ 4,01 bilhōes (FONSECA; COSTA, 2015).

Ressalta-se, também, o retorno do papel concentrador do Ministério da Saúde na conjuntura atual da AF brasileira dirigido ao contexto da atenção básica, que introduziu a convivência de dois tipos de provisão, descentralizada e centralizada. O ATFP estabeleceu-se de forma paralela, adotando mecanismos mais sofisticados, pela adoção do copagamento e na relaçáo público-privada, diferente do modelo público tradicional de fornecimento direto pelo SUS (SANTOS-PINTO, 2014), que denota arquitetura aos moldes de uma prestação de serviço de fornecimento de medicamentos.

Ainda que o papel centralizador se mostre eficiente no financiamento de medicamentos para programas estratégicos sob responsabilidade do Governo Federal, estas singularidades enfraquecem o processo de descentralização previsto no SUS, de forma geral. E mais: indicam dúvidas quanto à efetividade da descentralização prevista nas Políticas de Medicamentos e de AF. (SANTOS-PINTO et al., 2011).

Cabe salientar que, embora os dispêndios realizados pelo Ministério da Saúde, seja por meio de repasses para municípios ou pelo pagamento aos estabelecimentos credenciados do ATFP, estejam destinados ao financiamento de medicamentos no contexto da atenção primária em saúde, a fim de melhorar o acesso da população 
a esses bens em saúde, ambos seguem distintos mecanismos de financiamento, que trazem elementos para apoiar as comparaçôes de gastos entre eles.

Desde 2012, o gasto médio por habitante no ATFP já supera a contrapartida mínima do Ministério da Saúde no CBAF (de R\$ 5,10) e, em 2014, é maior (R\$ $11,25)$ que o valor mínimo acrescido das parcelas dos gestores estaduais e municipais (que totalizam $\mathrm{R} \$ 9,82$, todos em valores correntes). Ainda que a comparação dos valores mínimos per capita das três esferas de gestão do SUS definidos nas normas de financiamento do CBAF frente ao gasto médio por habitante no Programa ATFP para pagamento de medicamentos exija certa cautela, as diferenças reforçam o processo de fragilização do setor público e do maior direcionamento de recursos financeiros federais ao setor privado varejista credenciado ao Programa.

Essas disparidades de magnitude levantam discussóes sobre a existência de concorrência entre o programa ATFP e as farmácias básicas do SUS, principalmente pela competição na captação dos recursos e dos usuários, e não de uma complementariedade do ATFP ao fornecimento público. O Tribunal de Contas da Uniấo (2011) levantou argumento semelhante, uma vez que a concorrência entre programas pode levar a migração dos usuários para a alternativa com melhor prestação de serviços. Em um estudo que caracterizou o perfil dos usuários do ATFP e a participação e percepção destes em relação ao Programa, a partir de 1.073 entrevistas realizadas, em agosto de 2012, em 27 estabelecimentos privados credenciados distribuídos em 15 municípios de 14 estados; Carraro (2014) assinalou que apenas um pequeno percentual de usuários das farmácias do SUS migrou para o ATFP. Segundo o estudo, antes da criação do ATFP, 52\% dos entrevistados adquiriam seus medicamentos por desembolso direto nas farmácias privadas, 19\% os retiravam nas farmácias do SUS e compravam no comércio varejista, quando o produto não se encontrava disponível, e 16\% dependiam exclusivamente das farmácias do SUS, levando-a considerar que o Programa federal tem um papel complementar e não concorrencial à assistência farmacêutica pública, conforme a autora.

O elenco da vertente ATFP é basicamente restrito a medicamentos de uso na atenção primária, já que se destinam às condiçôes nosológicas de maior prevalência no território brasileiro. Excetuando algumas apresentaçôes das insulinas NPH e regular e da beclometasona para tratamento da asma, estes medicamentos também estão cobertos pelo Componente Básico da Assistência Farmacêutica, com os recursos financeiros transferidos automaticamente aos municípios. 
Identificou-se marcante representatividade dos gastos com medicamentos antihipertensivos e antidiabéticos orais e injetáveis. Além de participarem desde o início do processo de expansão do $\mathrm{PFPB}$, estes grupos terapêuticos guardam compatibilidade com a carga de doenças no cenário nacional, onde as doenças crônico-degenerativas já eram responsáveis por mais de 66\% da carga nacional de doença no final da década de 1990 (SCHRAMM et al., 2004). Atualização da carga da doença recentemente publicada, tomando por base o ano de 2008, continuou mostrando preponderância das doenças crônicas não transmissíveis (DCNT) em todas as regiôes do país, com destaque para as doenças cardiovasculares; os transtornos mentais, em especial a depressão; o diabetes mellitus e a doença pulmonar obstrutiva crônica (LEITE et al., 2015). Sabe-se também que a morbimortalidade conferida a essas condiçôes é maior na população mais pobre (SCHMIDT et al., 2011).

As DCNTs têm assumido papel crescente e preocupante em decorrência das transições demográfica, nutricional e epidemiológica ocorridas nas últimas décadas. Estudos epidemiológicos brasileiros, realizados a partir da medida casual da pressão arterial, registram prevalências de hipertensão de $40 \%$ a $50 \%$ entre adultos com mais de 40 anos de idade (BRASIL, 2011). O diabetes mellitus, qualificado atualmente como uma epidemia mundial, traz inúmeros desafios para todos os sistemas de saúde. Estima-se mais de seis milhóes de portadores de diabetes no Brasil, incorrendo em impacto econômico decorrente dos custos do tratamento da doença per si e de suas complicaçóes crônicas, como a doença cardiovascular, nefropatia, neuropatia e retinopatia. No Brasil, o diabetes e a hipertensão arterial constituem a primeira causa de hospitalizaçóes no SUS (BRASIL, 2011). O acesso a estes medicamentos reforça a relevância da atuação conjunta do Programa ATFP no enfrentamento de condições que afetam número bastante expressivo de brasileiros.

O grupo de medicamentos hipolipemiantes também resultou em montantes elevados de recursos pagos pelo Ministério da Saúde, ainda mais porque estes estão representados por um único fármaco, a sinvastatina, da classe das estatinas, que ocupa o terceiro maior volume nos gastos, mesmo sendo dispensado mediante copagamento pelos usuários. Segundo o Ministério da Saúde (DAB, 2006), indivíduos de alto risco com doença cardiovascular, especialmente com manifestaçóes de doença aterosclerótica, como cardiopatia isquêmica, doença cerebrovascular, devem ser tratados com estatinas, independente dos níveis de colesterol sérico basal. 
Caso singular é observado nos dispêndios do grupo dos antagonistas da angiotensina II, para tratamento da hipertensão, e que possui um único representante, a losartana potássica $50 \mathrm{mg}$. Este medicamento teve entrada tardia no ATFP, mas sozinho representou o segundo maior volume de pagamentos do período 2006-2014 (23,5\% do total de gastos), com a maior participação entre os três últimos anos analisados. Estes elementos sugerem mudança de padrão prescritivo dos médicos no tratamento da hipertensão, provavelmente decorrente dos efeitos adversos dos inibidores da enzima conversora de angiotensina (captopril e enalapril), como a tosse seca (DAB, 2013).

Medicamentos antiasmáticos só foram introduzidos no rol do ATFP em 2010, inicialmente por copagamento, passando a ser dispensados sem participação financeira por parte do usuário a partir de julho de 2012. Estes produtos possuem elevado valor de referência unitário, e apesar de a doença ser bastante prevalente em nosso meio, os gastos com tais medicamentos foram muito baixos no ATFP, embora com tendência crescente. Os anti-hipertensivos apresentaram gastos 25 vezes maior que os produtos para a asma, o que pode ter sido decorrente da introduçáo tardia destes últimos no Programa. Outro ponto que pode explicar esse comportamento é a diferença entre a prevalência da asma e da hipertensão, de 4,4\% e 21,4\%, respectivamente, no Brasil (IBGE, 2013). Além disso, podem ser considerados a variação sazonal dos sintomas da asma.

Embora não tenha sido objeto de análise neste artigo, chama a atenção o volume de gastos com as fraldas geriátricas, que foram introduzidas, em 2010, no ATFP e são fornecidas por sistema de copagamento. $\mathrm{O}$ montante de dispêndios no período 2006-2014 foi de quase $\mathrm{R}$ \$ 210 milhóes (2,6\% do total) e maiores que os dispêndios totais com medicamentos antiasmáticos. Trata-se de um insumo muito importante para atendimento da população idosa, que não possui uma política de financiamento específica pelos blocos de Assistência Farmacêutica do SUS. O Componente Básico da AF dirige a poucos materiais médicos para contracepção e preservativos, que são adquiridos e repassados pelo Ministério da Saúde, mas não inclui fraldas.

Em 2015, ganhou espaço, na mídia em geral, a proposta de cortes no Programa Farmácia Popular, fruto da crise econômica e fiscal brasileira e que encerrará a modalidade estatal Rede Própria. Em reunião da Comissão Intergestores Tripartite, com representantes dos gestores estaduais, municipais e do Governo Federal realizada em março de 2017, foi deliberado o fim do repasse de manutenção e de 
operacionalização das unidades de Rede Própria. As negociaçôes indicam que os valores orçamentários serão transferidos aos municípios, aumentando em alguns centavos o valor mínimo por habitante no CBAF (CONASEMS, 2017).

Outro aspecto interessante a ser apontado é a relativa concentração dos gastos no Programa ATFP com pagamentos a algumas empresas do comércio farmacêutico. Entre as 10 primeiras entidades em volume de pagamentos constam cadeias de redes que passaram por processo de fusão ocorridos nos últimos cinco anos, reproduzindo movimento similar presente na indústria farmacêutica, cuja ocorrência tem sido motivada pela redução de custos, ganhos de economia de escala e escopo em atividades de pesquisa e desenvolvimento, e a redução dos custos de distribuição (MAGALHÃES et al., 2003; KORNIS et al., 2014). A empresa Jamyr Vasconcellos S.A., proprietária das Drogarias Pacheco e que mais recebeu pagamentos no período (R\$ 518 milhôes), fundiu-se com a Drogaria São Paulo S.A. Em 2011, o mesmo aconteceu com a rede Drogasil S.A., que se aliou à Drogaria Raia S.A. A firma cearense Empreendimentos Pague Menos S.A., que ocupa a terceira posição nos pagamentos em nível nacional, ainda não passou por fusão ou aquisição, mas já existiram relatos nas publicaçôes do grupo Valor Econômico, em 2013, de abertura de negociaçóes com companhias de cadeias americanas (CVS Caremark Corp. e a Walgreen Co), na expectativa de melhoria de sua posição concorrencial entre as grandes redes (SILVA, 2014). É possível que essa transformação recente no segmento do comércio varejista nacional busque satisfazer aos mesmos objetivos e estratégias de melhoria da posição competitiva no setor acima citado (MAGALHÃES et al., 2003), mas poderá implicar em aumento na concentração de mercado.

A forte concentração de estabelecimentos credenciados e sediados na região Sudeste e, em especial, localizados entre Rio de Janeiro e São Paulo reflete o perfil demográfico presente no Brasil. Apenas estes dois estados correspondem a quase $30 \%$ da população brasileira. Além disso, certamente impactam nessa concentração certas características do perfil de adoecimento de suas populaçóes. Assim, por exemplo, enquanto a prevalência de hipertensão arterial está em torno de $23 \%$ nesses dois estados, nos estados da região Norte é de aproximadamente 14,5\% (IBGE, 2013). Outras condiçôes crônicas, como o diabetes mellitus, também apresentam diferenciais igualmente grandes.

O varejo farmacêutico pode ser composto por farmácias independentes e redes. Essas últimas, caracterizadas pela existência de mais de uma farmácia sob a mesma 
direção, são acompanhadas de vantagens competitivas que permitem compras diretamente nos laboratórios farmacêuticos, fruto da larga escala, diferenciando das aquisiçóes realizadas por meio do atacado, ou seja, pelos distribuidores farmacêuticos. O crescimento das redes tem sido impelido pelo crescimento nacional do consumo de medicamentos, por diversos fatores, como o envelhecimento populacional, extensão do acesso a medicamentos nas classes mais pobres (C e D), além da expansão do rol de produtos comercializados, como produtos cosméticos e higiene pessoal (FERRARI, 2010).

Por fim, faz-se sempre relevante salientar as limitaçóes inerentes à pesquisa em questão. A principal decorre do fato de o Ministério da Saúde, que coordena o ATFP, ser a principal fonte de dados do Programa. Outro aspecto, a paucidade de informaçôes facilmente acessíveis ao público levou à necessidade de se recorrer ao sistema e-SIC, que, mesmo tendo viabilizado o acesso a alguns dados náo divulgados, também possui restriçoóes, uma das quais se refere à baixa capacidade de se examinar a consistência do obtido. Além disso, nos pagamentos ao varejo farmacêutico credenciado no ATFP estão inseridos outros custos, como tributos, custos operacionais, serviços etc., além do valor do medicamento em si, logo, a comparação dos valores repassados dentro do CBAF é destinada apenas à aquisição, sem considerar a cadeia de custos, como os citados acima, dentre outros.

\section{Considerações finais}

O estudo lança luz sobre o importante volume de recursos dispendidos com pagamentos de medicamentos no Programa Aqui Tem Farmácia Popular, que atingiu a quase $\mathrm{R} \$ 8$ bilhóes no período estudado, em paralelo à expansão no número de usuários atendidos e de estabelecimentos credenciados.

Ainda que o verificado possa representar aumento de recursos no financiamento da Assistência Farmacêutica e, consequentemente, contribuir para uma maior disponibilidade de medicamentos, persiste a necessidade do desenvolvimento de ações eficientes na aplicação dos recursos e na prestação de serviços de qualidade e efetivos. Isso, principalmente, sobre os processos de dispensação de medicamentos no Programa Farmácia Popular, que não inclui obrigatoriamente orientação sobre o uso de medicamentos, fundamentais para seu uso adequado. 
A ausência de clareza na relação entre os modelos de provisão de medicamentos traz inúmeros desafios na garantia da complementariedade do Programa ATFP, conectado com as demais ações de saúde e sem assumir papel concorrencial com os serviços prestados no SUS. Embora, na atualidade, seja difícil conceber uma Administração Pública que possa executar integralmente todos os serviços de forma direta, sem contar com a participação do setor privado, problemas surgem quando se transforma o que deveria ser complementar em principal.

Finalmente, os aumentos expressivos nos gastos federais do Programa sob estudo devem ser objeto de monitoramento cuidadoso, já que sustentabilidade financeira é questão fundamental na viabilidade dos sistemas de financiamento de medicamentos, e os recursos no país para a assistência à saúde, aí incluída a assistência farmacêutica, são reconhecidamente escassos e insuficientes para as demandas já presentes e por vir. ${ }^{2}$

\section{Referências}

ASSOCIAÇÃO DA INDÚSTRIA FARMACÊUTICA DE PESQUISA (INTERFARMA). Guia Interfarma 2015. Sáo Paulo: INTERFARMA, 2015. Disponível em: <http:// www.interfarma.org.br/guia2015/site/guia/index.php?val=36\&titulo=Programa\%20 Farm\%C3\%A1cia\%20Popular>. Acesso em: 10 nov. 2015.

BRASIL. Lei no 10.742, de 6 de outubro de 2003. Define normas de regulação para o setor farmacêutico, cria a Câmara de Regulação do Mercado de Medicamentos - CMED e altera a Lei no 6.360, de 23 de setembro de 1976, e dá outras providências. Diário Oficial da União, 7 out. 2003.

Ministério da Saúde. Portaria GM no 2.084, de 26 de outubro de 2005. Estabelece os mecanismos e as responsabilidades para o financiamento da Assistência Farmacêutica na Atenção Básica e dá outras providências. Diário Oficial da União, 28 out. 2005.

Portaria $n^{\circ} 491$, de 9 de março de 2006. Dispóe sobre a expansão do Programa "Farmácia Popular do Brasil". Diário Oficial da União, 10 mar. 2006.

. Portaria no 3.237, de 24 de dezembro de 2007. Aprova as normas de execução e de financiamento da assistência farmacêutica na atenção básica em saúde. Diário Oficial da União, 26 dez. 2007.

. Portaria $G M$ no 2.982, de 26 de novembro de 2009. Aprova as normas de execuçáo e de financiamento da Assistência Farmacêutica na Atenção Básica. Diário Oficial da União, 30 nov. 2009. 
. Portaria no 4.217, de 28 de dezembro de 2010. Aprova as normas de financiamento e execução do Componente Básico da Assistência Farmacêutica. Diário Oficial da União, 29 dez. 2010.

. Portaria no 971, de 15 de maio de 2012. Dispóe sobre o Programa Farmácia Popular do Brasil. Diário Oficial da União, 17 maio 2012.

. Portaria $n^{o} 1.555$, de 30 de julho de 2013. Dispóe sobre as normas de financiamento e de execução do Componente Básico da Assistência Farmacêutica no âmbito do Sistema Único de Saúde (SUS). Diário Oficial da União, 31 jul. 2013. Disponível em: <http://bvsms.saude. gov.br/bvs/saudelegis/gm/2013/prt1555_30_07_2013.html>. Acesso em: 20 ago. 2015.

. A Gestão da Inovação no Fundo Nacional de Saúde. Brasília: Ministério da Saúde, 2014.

- Plano de ações estratégicas para o enfrentamento das doenças crônicas não transmissiveis (DCNT) no Brasil 2011-2022. Brasília: Ministério da Saúde, 2011. Disponível em: <http:// bvsms.saude.gov.br/bvs/publicacoes/plano_acoes_enfrent_dcnt_2011.pdf >. Acesso em: 18 out. 2015.

. DAB: Departamento De Atenção Básica. Estratégias para o cuidado da pessoa com doença crônica: hipertensão arterial sistêmica. Cadernos de Atenção Básica. Brasília: Ministério da Saúde, no 37, 2013. 128 p.

. DAB: Departamento DeAtenção Básica. Prevenção clínica de doenças cardiovasculares, cerebrovasculares e renais. Cadernos de Atenção Básica. Brasília: Ministério da Saúde, no 14 , 2006. 56 p. (Série A. Normas e Manuais Técnicos).

BRASIL. Ministério do Planejamento, Orçamento e Gestão. Secretaria de Orçamento Federal. Orçamentos da União exercício financeiro 2016: Projeto de Lei Orçamentária (volume II). Brasília: MPOG, 2015.

- Tribunal de Contas da União (TCU). Relatório de auditoria operacional: Farmácia Popular. Brasília: TCU, Secretaria de Fiscalização e Avaliação de Programas de Governo, 2011. BUENO, C. S.; MOREIRA, A. C.; OLIVEIRA, K. R. Preço dos medicamentos utilizados nas doenças cardiovasculares no Brasil. Rev Panam Salud Publica, v. 31, n. 1, p. 63, 2012.

CALIARI, T.; RUIZ, R. M. Os gastos públicos com medicamentos no período de 2002 a 2006. Revista de administração em saúde, v. 12, p. 167-76, 2010.

CARRARO W. B. W. H. Desenvolvimento econômico do Brasil e o Programa Aqui Tem Farmácia Popular: limitantes e potencialidades. 2014. Tese (Doutorado em Economia do Desenvolvimento) - Universidade Federal do Rio Grande do Sul. Porto Alegre; 2014. Disponível em: <http:// www.lume.ufrgs.br/bitstream/handle/10183/103962/000921903.pdf?sequence=1>. Acesso em: 15 set. 2015. 
CHAMA, B. L. T. et al. Trends in medicines procurement by the Brazilian federal government from 2006 to 2013. PLoS ONE, v. 12, n. 4, p. e0174616, Apr 2017. Disponível em: <https://doi. org/10.1371/journal.pone.0174616>. Acesso em: 7 ago. 2015.

CONSELHO NACIONAL DE SECRETARIAS MUNICIPAIS DE SAÚDE (CONASEMS). Nota Informativa no18/2017. Disponível em: <http://www.conasems.org.br/wp-content/ uploads/2017/04/Nota-encerramento-Rede-Própria-FPB.pdf>. Acesso em: 25 jul. 2017.

DATASUS. População residente estimativa para o TCU. Brasília. 2015. Disponível em: <http:// tabnet.datasus.gov.br/cgi/tabcgi.exe?ibge/cnv/poptuf.def>. Acesso em: 10 ago. 2015.

EMMERICK, I. C. M. et al. Farmácia Popular Program: changes in geographic accessibility of medicines during ten years of a medicine subsidy policy in Brazil. Journal of Pharmaceutical Policy and Practice, v. 8, n. 1, dez. 2015.

FERRARI, D. B. V. P. Estrutura de mercado e o varejo farmacêutico de Belo Horizonte. 2010. Dissertação (Mestrado em Economia) - Universidade Federal da Bahia, Salvador, 2010.

FONSECA, E. M.; COSTA, N. R. Federalism, the Economic-Industrial Health Care Complex and High-Cost Pharmaceutical Assistance in Brazil. Ciênc. Saúde Coletiva, v. 20, n. 4, p. 1.16576, abr. 2015.

HELFER, A. P. et al. Capacidade aquisitiva e disponibilidade de medicamentos para doenças crônicas no setor público. Rev Panam Salud Pública, v. 31, p. 225-32, 2012.

INSTITUTO BRASILEIRO DE GEOGRAFIA E ESTATÍSTICA (IBGE). Pesquisa de Orçamentos Familiares 2002-2003: primeiros resultados - Brasil e grandes regióes. Rio de Janeiro: IBGE, 2004. Disponível em: <http://www.ibge.gov.br/home/estatistica/populacao/ condicaodevida/pof/2002/pof200220032aed.pdf>. Acesso em: 4 nov. 2015.

. Pesquisa de Orçamentos Familiares 2008-2009: Despesas, Rendimentos e Condiçóes de Vida. Rio de Janeiro: IBGE, 2010. Disponível em: <http://www.ibge.gov.br/home/estatistica/ populacao/condicaodevida/pof/2008_2009/POFpublicacao.pdf>. Acesso em: 4 nov. 2015.

- Pesquisa Nacional de Saúde 2013: percepção do estado de saúde, estilos de vida e doenças crônicas - Brasil, Grandes Regiôes e Unidades da Federação. Disponível em: <ftp://ftp. ibge.gov.br/PNS/2013/pns2013.pdf>. Acesso em 15 jul. 2017.

KORNIS, G. E. M.; BRAGA, M. H.; PAULA, P. A. B. Transformaçóes recentes da indústria farmacêutica: um exame da experiência mundial e brasileira no século XXI. Physis: Revista de Saúde Coletiva, v. 24, n. 3, p. 885-908, set. 2014.

LEITE, I. DA C. et al. Carga de doença no Brasil e suas regiōes, 2008. Cadernos de Saúde Pública, v. 31, n. 7, p. 1.551-1.564, jul. 2015.

LU, Y.; HERNANDEZ P.; ABEGUNDE D. EDEJER T. The World Medicines Situation 2011: Medicines Expenditures. Geneva: WH, 2011. 
MAGALHÃES L. C. G. et al. Estratégias empresariais de crescimento na indústria farmacêutica brasileira: investimentos, fusóes e aquisiçôes, 1988-2002. Brasília: Ipea, 2003. (Texto para Discussão, n. 995).

ORGANISATION FOR ECONOMIC CO-OPERATION AND DEVELOPMENT. Pharmaceutical Pricing Policies in a Global Market. Paris: OECD, 2008.

OSORIO-DE-CASTRO, C. G. S.; LUIZA, V. L.; CASTILHO, S. R.; OLIVEIRA, M. A.; MARIN, N. (Orgs.). Assistência Farmacêutica: gestão e prática para profissionais de saúde. Rio de Janeiro: Fiocruz, 2014.

PANIZ, V. M. V. et al. Free access to hypertension and diabetes medicines among the elderly: A reality yet to be constructed. Cad. Saúde Pública. Rio de Janeiro, 26(6):1.163-1.174, jun, 2010. PEREIRA, M. A. Programa Farmácia Popular no Brasil: uma análise sobre sua relação com o Complexo Econômico-Industrial da Saúde e os programas estratégicos do Governo Federal. 2013. Dissertação (Mestrado Profissional em Saúde Pública) - Escola Nacional de Saúde Pública Sérgio Arouca, Rio de Janeiro, 2013.

PINTO, C. D. B. S. O Programa Farmácia Popular do Brasil: modelo, cobertura e utilização frente à Política Nacional de Medicamentos. 2008. Dissertação (Mestrado em Saúde Pública) Escola Nacional de Saúde Pública Sérgio Arouca, Rio de Janeiro, 2008.

SANTOS-PINTO, C. D. B.; COSTA, R. N.; OSORIO-DE-CASTRO, C. G. S. Quem acessa o Programa Farmácia Popular do Brasil? Aspectos do fornecimento público de medicamentos. Ciência \& Saúde Coletiva, v. 16, n. 6, p. 2.963-2.973, 2011.

SANTOS-PINTO, C. D. B. Copagamento como ampliação do acesso a medicamentos: Programa Farmácia Popular do Brasil. In: OSORIO-DE-CASTRO, C. G. S.; LUIZA, V. L.; CASTILHO, S. R.; OLIVEIRA, M. A.; MARIN, N. Assistência farmacêutica: gestáo e prática para profissionais da saúde. Rio de Janeiro: Editora FIOCRUZ, 2014. 472 p.

SCHMIDT, M. I. et al. Doenças crônicas não transmissíveis no Brasil: carga e desafios atuais. The Lancet, v. 6.736, n. 11, p. 60.135-60.139, May 2011.

SCHRAMM, J. M. A. et al. Transição epidemiológica e o estudo de carga de doença no Brasil. Ciênc. Saúde Coletiva. Rio de Janeiro, v. 9, n. 4, p. 897-908, dez. 2004.

SILVA, R. M. Programa “Aqui tem Farmácia Popular": expansão entre 2006-2012 e comparação com os custos da assistência farmacêutica na Secretaria Municipal de Saúde do Rio de Janeiro. 2014. Tese (Doutorado) -Universidade do Estado do Rio de Janeiro, Rio de Janeiro, 2014.

SILVA, R. M.; CAETANO, R. Programa "Farmácia Popular do Brasil": caracterização e evolução entre 2004-2012. Ciência \& Saúde Coletiva, v. 20, n. 10, p. 2.943-2.956, out. 2015.

VIEIRA, F. S. Gasto do Ministério da Saúde com medicamentos: tendência dos programas de 2002 a 2007. Rev Saúde Pública, v. 43, n. 4, p. 674-681, jun. 2009. 
VIEIRA, F. S.; ZUCCHI, P. Financiamento da assistência farmacêutica no sistema único de saúde. Saúde Soc, v. 22, n. 1, p. 73-84, mar. 2013.

WHO Collaborating Centre for Drug Statistics Methodology. Anatomical-Therapeutic-Chemical classification index. Oslo: Norwegian Institute of Public Health; 2015. Disponível em: <http:// www.whocc.no/atc_ddd_index/>. Acesso em: 10 ago. 2015.

\section{Notas}

${ }^{1}$ Na época da realização da pesquisa, a Portaria no 971/2012 regulamentava o Programa ATFP. Em 2016, essa Portaria foi revogada e substituída pela Portaria no.111, de 28/1/2016. Permaneceram inalterados o elenco e as indicaçóes de uso dos medicamentos no Programa.

${ }^{2}$ R. M. da Silva participou da concepção e desenvolvimento do artigo, coleta e tabulação de dados, interpretação dos dados e redação do artigo. R. Caetano participou da concepção do artigo, interpretação dos dados, redação e revisão crítica do texto e aprovação final. 


\section{Abstract}

Expenditures with payments in the "Aqui Tem Farmacia Popular" Program: evolution between 2006-2014

In 2004, the federal government has announced a new mechanism to improve the access of the Brazilian population to medicines, called "Programa Farmácia Popular do Brasil". The model named "Aqui Tem Farmácia Popular" (ATFP), started in 2006 with the participation of the private retail pharmacies, has been the main responsible for the expansion of this form of provision. This article examined the expenditures of the Ministry of Health with payments of medicines to accredited private sector pharmacies to the ATFP Program in 2006 to 2014 . We used data from secondary sources, such as the National Health Fund, SAGE database and direct contact with the e-SIC system. Were spent BRL 7.9 billion with the ATFP, with strong growth pattern after exemption of copayment, since 2011. Medicines for treatment of hypertension totaled $60 \%$ of expenditures, followed by the antidiabetic (19\%) and dyslipidemia (14\%). Losartan potassium and simvastatin were the major drugs in spending. The significant increases in federal expenditures should be the object of careful monitoring, since financial sustainability is a fundamental question on the viability of the financing systems of medicines.

Keywords: Pharmaceutical Services; drug costs; health expenditures; government programs; Farmacia Popular Program. 